\title{
Entrevista a Clara Jourdan y a Luisa Muraro de la Libreria delle donne de la ciudad de Milán, Italia
}

\author{
Maria Marta Herrera \\ Universidad de Buenos Aires, Argentina Universidad Nacional de La Plata, Argentina \\ herrera.maria.marta@gmail.com
}

A mediados del siglo XX, los reclamos por la igualdad, la emancipación y la ciudadanía, entre otras cuestiones, impulsaban la progresiva participación de las mujeres en el espacio público. La lucha por el sufragio concluía con éxito en la mayoría de los países occidentales. El acceso a la educación, incluso universitaria, también se fortalecía, permitiendo progresivamente que más mujeres accedieran a profesiones antes exclusivamente masculinas. Cada vez más mujeres se independizaban del sistema patriarcal. Sin embargo, como señala Simone de Beauvoir en El Segundo Sexo (1949), a pesar de todos los logros alcanzados, la condición de oprimidas de muchas mujeres estaba lejos de ser superada. Su obra examinó, e intentó dar una respuesta, a este dilema.

En este sentido, algunos grupos de mujeres dentro del movimiento feminista comenzaron a pensar que la lucha por la emancipación y la libertad no se alcanzaba exclusivamente con el acceso a una ciudadanía política, con la independencia económica, ni con la educación, sino que era necesaria una transformación simbólica y política de las mujeres. Se trataba de rechazar el lugar de víctimas en el sistema patriarcal para pensarse desde el propio mundo simbólico, afectivo, relacional de y para las mujeres.

A partir de los años 70, el feminismo de la diferencia surge como una alternativa a esos objetivos que se había planteado el feminismo de la igualdad, tanto en EEUU como en algunos países europeos. En esos años, se afianzaron en Italia diferentes grupos del pensamiento y la política de la diferencia sexual. Muchas de las mujeres que lo integraban provenían de los partidos de izquierda, desencantadas por el persistente abandono de sus reclamos dentro de las políticas partidarias tradicionales como, por ejemplo, Carla Lonzi. Ella y muchas otras, inspiradas por la liberación de mayo del 68 , asumieron la práctica de la autoconciencia como el motor para construir el pensamiento de la diferencia sexual y como una manera de hacer política de las mujeres por fuera de las instituciones, en comunidades o en centros de divulgación como la Libreria delle donne en la ciudad de Milán. Es decir que se trataba de gestar nuevas formas de relación entre mujeres basadas en el reconocimiento de una/s genealogía/s femenina/s sin relación con el mundo de los varones, patriarcal y falocéntrico. De ahí la importancia que, para ellas, adquiere la búsqueda de referencias simbólicas entre mujeres, plasmada en la noción de affidamento. Se trata de dar cuenta de la potencia no sólo simbólica sino política de reconocer en otras mujeres, interlocutoras. Por ello, la diferencia sexual es una categoría principal para esta perspectiva, a partir de la cual se da cuenta de la experiencia de lo vivido, se reflexiona y se hace política.

Luisa Muraro es una de las figuras más representativas de este pensamiento y una de las fundadoras de la Librería. Es filósofa, estudió en la Universidad Católica y fue docente en la Universidad de Verona, donde crea la comunidad filosófica de Diotima. L'ordine simbolico della madre (1991) [El orden simbólico de la madre (1994)] es un libro fundamental para entender las nociones de "autoridad materna", "affidamento" 
o "continuum materno" que vertebran este feminismo. Lingua materna, scienza divina. Scritti sulla filosofia mistica di Margherita Porete (1995), Le amiche di Dio (2001), Il Dio delle donne (2005), La signora del gioco (2006), Al mercato della felicitá (2009), Dio è violent (2012), L'anima del corpo (2016) son algunos de sus libros, varios de los cuales han sido traducidos al castellano.

Clara Jourdan, estrecha colaboradora de la Libreria delle donne, es profesora de escuela media en Derecho y Economía Política, actualmente no ejerce. Está vinculada, además, al Grupo Duoda de Barcelona y es docente en el Master presencial y online sobre el pensamiento de la Diferencia sexual en la Universidad de Barcelona. Algunas de sus publicaciones son La politica del Desiderio. Originalità del femminismo italiano (2010), Cuando el derecho se convierte en una barrera simbólica (2009), El enigma de la mujer maltratada (2009), La Libreria de mujeres en el presente (2008), Educar en relación. Dar sentido a la diferencia sexual (2001), El sentido de un tesauro como vocabulario de la política (1999). Además, ambas tienen numerosas y continuas participaciones en las dos revistas de la Librería, Via Dogana y Aspirina, y realizan continuamente contribuciones online en la página web http://www.libreriadelledonne.it/

Por razones de agenda de las entrevistadas, el encuentro tuvo dos partes: en la primera, entrevistamos a Clara Jourdan, quien prefirió conversar sobre temas del feminismo desde una perspectiva del pensamiento de la diferencia sexual; en la segunda, escuchamos el testimonio de Luisa Muraro sobre el origen y construcción de la Librería.

\section{Primera parte}

MMH: A partir del movimiento Ni Una Menos en Argentina, se ha planteado como tema de reflexión la relación entre nuevas generaciones de feministas. ¿Qué podrías decirnos al respecto desde la librería de Mujeres?

CJ: En general, las jóvenes del movimiento Ni Una Menos de Italia, en particular de Milán, nos conocen. Hay, sobre todo, relaciones personales, no tanto institucionales. Ahora bien, la relación con las nuevas generaciones la podemos ver en la construcción de nuestra página web. En su momento, cuando empezamos, hace más de 15 años atrás, estas jóvenes mujeres -que ahora ya tienen 40/50 años-pensaron que era muy importante generar espacios para hacer política en las redes. Para mí, era una manera más de difundir lo que hacía la librería; en cambio, ellas veían allí la posibilidad de relaciones de intercambio político en red, un trabajo no solo de pensamiento sino también práctico. De manera esporádica, se siguen sumando jóvenes en la construcción de la página web donde ahora, también participamos las mujeres de mi generación, es decir de los '70. Luisa Muraro, por ejemplo, y estas mujeres más jóvenes.

Es cierto, también, que a nuestros encuentros vienen pocas jóvenes. Pero, hace dos años, un grupo de jóvenes franceses (varones y mujeres), buscando en internet información de un tipo de pensamiento que estuviera por fuera de lo institucional o de las organizaciones, se encuentra con nuestro libro Non credere di avere dei diritti (1987) [No creas tener derechos (1991)] y se apasionaron tanto que lo tradujeron al francés. Es un texto de hace más de 30 años que ellos encuentran actual y que nunca había sido traducido al francés, solo al español, al inglés, al alemán. Entonces, ahí se generó una relación. Luego, vinieron a visitarnos para resolver algunas dudas que tenían. Algunas de nosotras fuimos a Paris y a otras ciudades de Francia para presentarlo. Es un grupo muy joven de estudiantes universitarios que armó una pequeña editorial.

También, estamos relacionadas con otros grupos en Italia. En este momento, especialmente, con grupos de lesbianas con quienes hemos estado discutiendo el tema de la maternidad subrogada. Con ellas nos hemos sentido en sintonía, ya que pensamos que esta maternidad subrogada es una forma de borrar a la madre. A raíz de esta discusión, estos grupos de lesbianas se separaron de los grupos gays con quienes compartían la lucha por los derechos incluidos bajo el paraguas, digamos, de la homosexualidad. Ahora, se unieron a nosotras en tanto mujeres por la cuestión de la maternidad subrogada, cuestionando la primacía de los varones gays 
dentro del movimiento que, por supuesto, están a favor de la maternidad subrogada y de ir a "comprarse un hijo/a a América" como fue el caso de un conocido político y su compañero.

MMH: Como docente, ¿vos podés introducir los temas del feminismo en la currícula?

CJ: Yo ya estoy jubilada, pero claro, lo he hecho siempre, porque en Italia tenemos la libertad de enseñanza. Desde los 70, las feministas hemos introducido estas temáticas en nuestra práctica docente. Yo enseñaba derecho y economía política y siempre enseñé desde esta perspectiva. Aquí vienen a menudo escolares a visitar la librería con sus profesoras, ya nos conocen. Pero es cierto que, como docentes feministas, actuamos a un nivel individual, no de manera generalizada para insertar esto oficialmente en los programas, evitando que se vuelva algo burocrático. Creo que una política burocratizada de las mujeres es lo peor: se empieza a hablar de desigualdad, de paridad. Se sostiene así una idea de mujer como un ser inferior. En cambio, cuando una profesora desde su deseo y su libertad enseña estos temas, surgen cosas muy interesantes. No hay necesidad de que sea algo organizado institucionalmente. Yo creo más en las redes individuales, en unirme con una colega con quien compartimos estos intereses. Así se va difundiendo [es lo que hizo históricamente el feminismo]. El punto estaba en los intercambios personales entre las mujeres y en el involucrarse. Lo que revolucionó el feminismo fue el carácter personal de esas relaciones.

MMH: En nuestro país se da el debate entre un feminismo institucionalizado y una práctica feminista. ¿Vos estarías en contra de esta institucionalización, entonces?

CJ: No se trata de algo espontáneo. Estamos hablando de una práctica consciente, pero también de un pensamiento, ya que se reflexiona, se discute, se evalúan las situaciones, las dificultades. Entonces, es una práctica que involucra especialmente lo personal. Hay una implicación personal, desde allí se puede involucrar a los otros.

MMH: ¿Qué opinión te merecen las manifestaciones regresivas en torno a los logros adquiridos por las luchas de mujeres? ¿Confiás en la potencia del movimiento feminista frente a esta situación?

CJ: Es una pregunta difícil. Es cierto que hay muchos retrocesos en diversas partes, pero las mujeres siguen yendo para adelante, lo que hace que estemos en una permanente tensión. El caso del movimiento \#MeToo en el affaire Weinstein, en el que se cree únicamente en la palabra de la mujer, es algo nunca visto en la historia. En el pasado había que demostrar con pruebas lo que había ocurrido, mientras que ahora creyeron en lo que decían las mujeres en todo el mundo, en los medios y sobre hechos que habían ocurrido muchos años atrás. Ha sido un cambio importantísimo que nos señala que el patriarcado ha terminado porque no solamente nosotras no creemos en su poder sino los varones, los medios, etc., y que produjo que muchos varones perdieran sus trabajos, en realidad, sus puestos de poder. Pero también es cierto que hay retrocesos, especialmente, cuando se piensan en relación a la pobreza, en los barcos de inmigrantes desesperados que llegan acá a Italia en situaciones infrahumanas, donde no hay distinción entre varones y mujeres, por ejemplo.

MMH: En las imágenes y en los medios se habla de los varones inmigrantes especialmente. Cuando, en realidad, si se toman imágenes de un niñx muerto significa que también hay una madre de ese niñx. A nosotras nos impacta profundamente el resurgimiento de la violencia contra lxs inmigrantes y contra las mujeres en particular.

CJ: Es cierto que detrás de esos niños hay mujeres. Muchos de ellos son productos de violaciones que han sufrido en estos viajes, que callan para no estigmatizar aún más a los inmigrantes. Por otro lado, el recrudecimiento de la violencia contra las mujeres que mencionas está, para mí, relacionado con el hecho de que hay más libertad femenina y muchos varones no la aceptan. Entonces, responden al conflicto con las mujeres de manera violenta. Luego, es un signo de que algo ha cambiado y que los varones no pueden aceptarlo. No ven en eso una ocasión de libertad. Esto es un problema porque hay varones que lo aceptan, que reflexionan, que escriben, pero siguen siendo muy pocos. También es cierto que, si bien hay una violencia persistente, no se puede ya renunciar a la libertad que hemos alcanzado. Milagros Rivera Garretas, del grupo de Duoda, Barcelona dice que estos varones no soportan la grandeza femenina, como sucede en muchos casos 
de asesinatos de mujeres, donde luego el compañero/la pareja se suicida. No sé si es aplicable a todos los casos, pero la explicación de Milagros no deja de ser plausible.

$\mathrm{MMH}$ : ¿Estarías, entonces, de acuerdo con el concepto de "femicidio" como una violencia específica contra las mujeres?

CJ: Sí, claro. Acá, en Italia, aceptamos totalmente el término. El varón practica una violencia en particular contra las mujeres. Si bien se acepta la categoría "femicidio", no figura en el código penal, aunque se toma el homicidio de una mujer, por ser mujer, como un agravante. Sí, en cambio, se ha incorporado la figura del acoso que permite a los jueces intervenir.

Hubo un cambio enorme en los últimos 40 años sobre lo que significa ser mujer. Aunque a veces parezcan escasos los procesos de cambio, tenemos que pensar en el curso histórico y en lo que han logrado las mujeres a nivel simbólico y en la práctica. Creo que, a pesar de la persistencia de los hechos de violencia contra las mujeres, los movimientos como el \#MeToo son escuchados, movilizan, esto no deja de ser bueno. En cambio, me preocupa mucho el tema de la maternidad subrogada, donde se crean niños como un producto comercial, a pedido. Me pregunto qué mundo crearán estos niños, nacidos para complacer el deseo de alguien. Niños sin madre, me resulta algo muy inquietante en este momento, así como la extrema pobreza de los inmigrantes que llegan a nuestro país. Especialmente, el surgimiento de un racismo exacerbado que no era un problema en Italia. Yo pienso que algo muy importante en torno a esto es que la amenaza que se percibe respecto de los inmigrantes es porque cuando se habla de inmigrantes, se piensa sólo en varones. Las mujeres inmigrantes están invisibilizadas.

MMH: ¿Qué puedes decirnos sobre la llamada "ideología del género" con la que se acusa al feminismo?

CJ: Acá también se usa y el Vaticano contribuyó a promocionarla, pero no se entiende muy bien qué significa. En principio, parecía atacar la educación sexual en las escuelas. En Italia está más relacionado con las instituciones. El género es una categoría que está burocratizada. Es cierto que, para mí, el uso de la categoría "género" lo que hace es borrar la diferencia sexual. Y, en consecuencia, no creo que contribuya a la libertad de las mujeres. Al final, si tú borras los géneros, se sostiene la primacía del varón y borras a las mujeres, borras la diferencia sexual femenina. En cuanto a la educación, pareciera en este modelo que no cuenta si soy varón o mujer cuando en realidad, yo soy libre en tanto mujer o como mujer, no independientemente de mi sexo. En este sentido, los estudios queer o LGBTQ pueden ser entendidos como una búsqueda libre de la diferencia sexual pero no me parece que sea correcto pensarla como una cancelación.

Cuando en la Libreria delle donne hablamos de diferencia sexual, es desde un sentido libre, no de una diferencia sexual encarcelada como era en el pasado, donde los varones eran así y las mujeres de otra manera. Lo que hemos conquistado con la libertad femenina es un sentido libre de la diferencia. Ahora, no hay un modelo de femineidad en sentido estricto, más allá de lo que los mass media puedan querer mostrarnos.

$\mathrm{MMH}$ : Me interesa que nos señales tu posición con respecto al aborto. En la página web de la Libreria delle donne me llamó la atención una afirmación de Luisa Muraro: "(el aborto) es una potestad del cuerpo de la mujer que decreta injustamente, poner fin a una vida que comienza”.

CJ: Estoy de acuerdo con Luisa. Una vida puede seguir adelante si tiene el sí de la madre. Éste es el firme punto de partida. Luego, si una mujer no siente que es posible seguir adelante, aún si parece injusto, no hay nada que decir. No se puede prohibir a una mujer que aborte. ste es el punto. Desde el punto de vista jurídico, desde 1978, no se puede prohibir el aborto en Italia. Decir que está gozando de un derecho, me parece mal. Una mujer que decide abortar está diciendo que no puede o no quiere llevar a término un embarazo y eso es lo que hay que respetar. En nuestra ley, no se dice que la mujer tiene el derecho de abortar sino que debe respetarse su decisión de no seguir adelante con el embarazo. Cuando se habla de derechos, se está hablando con una mentalidad jurídica, con una mentalidad masculina, de los derechos del hombre que se transfieren a la mujer como el derecho a abortar. Es un modo de pensar el cuerpo de la mujer como si fuera un cuerpo masculino, un cuerpo que tiene derechos. En cuanto al aborto, es un tema delicado porque hay una potestad de ese cuerpo femenino. Por eso, en su momento, se discutió si había que hablar de legalización o 
despenalización. Simbólicamente, me parece más importante sostener la idea de despenalización (que luego se descartó en nuestra ley por la figura de legalización) porque pone en evidencia el respeto de la voluntad de la mujer, no del Estado que decide si lo puedes hacer o no. En este sentido, puede haber mujeres que estén en contra de abortar pero que aceptan que no pueden prohibir a otras que desean hacerlo.

Por último, piensa dentro de la tradición cristiana-católica, a María se le anuncia el Arcángel Gabriel y le pregunta si ella quiere tener al hijo de Dios. De ninguna manera, le es impuesto, en esta tradición hay un fuerte posicionamiento acerca de la libertad de la mujer que puede decir sí o no al embarazo.

\section{Segunda Parte}

MMH: Nos interesaría que nos contara cómo se originó la Libreria delle donne. Sabemos que está escrito, en parte, en el libro Non credere di avere dei diritti, pero nos interesa su testimonio.

LM: La librería abre en 1975, ¡hace un montón de tiempo! Es cierto que yo soy socia fundadora de la librería. En aquel entonces yo escribía documentos, textos, que era lo que me gustaba y sigo haciendo. Había otro grupo que tomaba más decisiones como Lía Cigarini, Elena Medi, Giordana Masotto (primera bibliotecaria) y que estaban relacionadas con el grupo Psychanalise et Politique, de Paris quienes habían abierto una librería en la Rue des Saints-Pres. Creo incluso que la siguen teniendo allí. La idea de la librería viene de esta relación. Yo estaba muy conectada con este grupo, fui parte del movimiento. Discutimos durante unos nueve meses, más o menos, la construcción de la librería. Nos pusimos, entonces, a buscar plata, porque siempre hemos sido una librería independiente. Nunca hemos usado, ni usamos, fondos públicos para poder mantener esta independencia. Milán era y es una ciudad más bien rica, donde había mujeres ricas. Una ciudad donde siempre hubo un protagonismo femenino, en todo sentido. Desde los tiempos de la Edad Media, con Guglielma [Boema, siglo XIII], las mujeres siempre tuvieron un rol importante, aunque no necesariamente público. Una ciudad, pues, donde las mujeres se han encontrado bien en términos de clase.

Una parte de la plata que necesitábamos, la obtuvimos vendiendo obras de arte de las artistas que nos las regalaban. A mí no me gusta vender ni pedir plata, pero tenía que hacer mi parte. Y, así, logré algo pequeño pero importante: contacté a una señora rica, de la alta burguesía milanesa, muy simpática, cuyo marido era escribano. Nosotras, para armar nuestra cooperativa, necesitábamos un escribano. Este escribano tenía su estudio en la calle más prestigiosa de Milán, Vía Montenapoleone. Cuando armamos nuestra cooperativa civil, tengo el vivo recuerdo de ir juntas, alegres, festivas, algunas elegantes, al acto inaugural. Todavía la librería no existía. La abro yo, el 15 de octubre de 1975, expresamente el día de Santa Teresa de Jesús. Cuando les contaba a las feministas españolas la importancia de esa fecha para mí, no entendían nada, y me miraban con ojos azorados: ¿Cómo una feminista se preocupaba por Teresa de Ávila? Sobre todo porque el dictador Franco había sido un devoto de ella y andaba por toda España con una reliquia. Luego, me comprendieron. Para mí, Teresa de Ávila fue una mujer católica, una política muy hábil amenazada por la Inquisición, pero que supo protegerse, y una excelente escritora. Ella perdura en su legado, mientras que Franco no ha dejado nada salvo su dictadura.

Ustedes, los argentinos, saben de dictaduras también. Aquí nos visitó Hebe de Bonafini. Recuerdo que Clara le hizo una pregunta bastante ingenua y Hebe le respondió: "Mi querida, no pasas una puerta y te conviertes en una madre de la Plaza de Mayo. Para convertirte en una madre, en este sentido político, ¡cuánto hemos caminado, cuánto debemos caminar aún en esa Plaza de Mayo! ¡Cuánta fatiga y cuánto trabajo en esta lucha!". Hay todo un trabajo simbólico de la maternidad de las madres de Plaza de Mayo.

Volviendo al feminismo en Italia, esto de lo simbólico está relacionado con este lugar también. No se combate sólo con la sociología, con los números, con la paridad, sino, sobre todo, cambiando la mirada, la cabeza, las relaciones, el orden simbólico. La política de lo simbólico es importantísima para que la violencia del otro no vaya dentro, muy adentro de tu alma para matarte. Es cierto que hay mujeres que no lo logran, pienso en mi madre que era una mujer muy dura que vivía en una sociedad más violenta que ahora. Las 
mujeres han aprendido a defenderse, aunque persiste la creencia en algunas de ellas de que en las relaciones amorosas se puede cambiar al violento.

MMH: Entre la primera y segunda manifestación de Ni Una Menos, hubo voces que señalaban un recrudecimiento de la violencia a partir de las crecientes denuncias, una especie de reacción de los varones. Según lo que usted menciona antes, ¿no estaría de acuerdo en que hay un incremento de la violencia luego de estas manifestaciones?

LM: Yo no tengo datos precisos para confirmar esta idea, pero tampoco la excluyo. Hay, evidentemente, muchas más denuncias gracias al ejercicio de la libertad femenina pero precisamente esta independencia femenina es el problema que deben resolver algunos varones. Porque la ven como un gran problema. Les dan trabajo, puestos, apoyo, pero siempre y cuando sean respetuosas de una idea de mujer sumisa (...)

Volvamos a la historia de la Librería. El 15 de octubre la abrimos. Teníamos pocos libros al principio, pero iban llegando. A los quince días, llegó nuestra bibliotecaria Giordana Masotto, muy inteligente. Todo empezó sin burocracia. Todas las decisiones se tomaban a partir de nuestras relaciones. Me acuerdo de una vez en Via Dogana, donde estuvimos anteriormente, que estábamos sentadas en el piso porque el espacio era chico, y una joven llamada Caterina, se levantó y me dijo: “Tú, Muraro, eres una mierda”. No lo recuerdo como una ofensa sino todo lo contrario. Pues así comenzamos de una manera muy vivaz, era la explosión del feminismo en Italia, en Europa, a mitad de los años 70. La librería estaba siempre llena. Tú, Clara, viniste después, cuando salió el libro Non credere di avere dei diritti en 1987. Fueron tiempos de mucho empuje, ahora cuesta mantenerla. No sé cómo será en Argentina, pero aquí las librerías están cada vez peor, muchas están cerrando. Es necesario mucho esfuerzo, creatividad.

Escribimos nuestro manifiesto en 1975 y a los diez años hicimos el libro Non credere di avere dei diritti que tuvo amplia difusión. La librería se conformó como un centro de ideas bastante importante, no el único por supuesto, pero sí uno muy activo en Milán, incluso en gran parte de Italia. También, para hacer conocer nuestras ideas íbamos a Roma, a la Casa Internacional de Las Mujeres, que existe todavía, y es un lugar muy lindo. Tenemos dos documentales sobre nuestra historia: La politica del Desiderio, donde contamos nuestra experiencia, y La libreria delle donne que se encuentra en una página web de Milán, MemoMi ${ }^{1}$

Parece que la ciudad está bastante orgullosa de nuestra librería.

Cuando nos mudamos a esta dirección [Via Pietro Calvi 29] en el 2001, hicimos una gran fiesta y había gente en toda la calle porque no entraba en el local. Ahora, en cambio, es una lucha que la gente se acerque físicamente al lugar, porque nos relacionamos mucho más a través de internet.

Dentro de nuestra política de las mujeres está, como decirlo, "darnos la importancia en el modo justo": tener relaciones no amables, sino verdaderas. Lo he sentido siempre así. Hay momentos más difíciles que otros. Las mujeres que hacemos la librería no somos una comunidad unificada, más bien somos pequeñas tribus, puesto que nuestra práctica política es la relación dual. Las que simpatizan entre sí construyen un lazo entre ellas por sus intereses comunes, y otras hacen otras uniones.

Por supuesto que recuerdo momentos de dificultad, por ejemplo, una reunión del sitio web. Llega Pat Carr, la encargada del comic Aspirina desde hace mucho tiempo, comienza a increpar y a tratar muy mal a una de las fundadoras del sitio web, más joven que yo. Yo soy de las fundadoras "jurásicas". Siempre me recuerdan una frase que yo pronuncié en ese momento: “Tú, Pat, no puedes tratarla mal porque ella es para nosotras una autoridad. Nosotras reconocemos en ella una autoridad”. Esta afirmación tuvo una cierta eficacia. Ésta es la idea de autoridad que nosotras defendemos: relaciones de autoridad sin poder. La autoridad siempre se asocia con el poder: quien tiene autoridad, tiene poder. Pero el poder siempre tiene que ser limitado, porque quita la libertad de las personas. Nosotras no estamos contra la autoridad, sino más bien por la autoridad pero contra el poder. Sabemos que ésta arrastra consigo al poder, por eso nuestra máxima es: el máximo de autoridad, con el mínimo de poder. Es una fórmula matemática "max/min” que significa el máximo rendimiento con el mínimo de inconvenientes, se utiliza, por ejemplo, para calcular la construcción de un camino en la montaña. 
Nosotras lo aplicamos a nuestra política. Esto es lo que hacemos... Dejemos acá... ¿Quieren ahora tomar una copita de vino?

Traducción del italiano: María Marta Herrera

\section{Notas}

1. MemoMi (productor) (2014). La libreria delle donne. Recuperado de https://memomi.it/it/00009/libreria-delle-don ne/ricerca.html 